\title{
Impact of generalist predation on two weed biocontrol agents in New Zealand
}

\author{
Quentin Paynter ${ }^{1 *}$, Paul Peterson ${ }^{2}$, Samantha Cranwell ${ }^{3}$, Chris Winks ${ }^{1}$ and Zane McGrath ${ }^{1}$ \\ ${ }^{1}$ Manaaki Whenua - Landcare Research, Private Bag 92170, Auckland, New Zealand \\ ${ }^{2}$ Manaaki Whenua - Landcare Research, Private Bag 11052, Manawatu Mail Centre, \\ Palmerston North 4442, New Zealand \\ ${ }^{3}$ School of Geography Earth and Environmental Sciences, University of Birmingham, Edgbaston, \\ Birmingham B15 2TT, United Kingdom \\ ${ }^{*}$ Corresponding author: PaynterQ@LandcareResearch.co.nz
}

\begin{abstract}
The broom leaf beetle (Gonioctena olivacea) and the Honshu white admiral butterfly (Limenitis glorifica) have been introduced into New Zealand as biocontrol agents of the weeds Scotch broom (Cytisus scoparius) and Japanese honeysuckle (Lonicera japonica) respectively. However, neither agent has been successful yet. Larval predation of these species could be a factor affecting their success, and this hypothesis was tested using various predator-exclusion treatments. Survival of broom leaf beetle larvae increased c. five-fold by sleeving Scotch broom seedlings in fine mesh. In contrast, survival was unaffected by excluding either crawling predators using sticky barriers or larger predators using chicken wire. Survival of Honshu white admiral butterfly larvae increased c. ten-fold by excluding either crawling predators using sticky barriers or flying predators using a fine-mesh sleeve. Simultaneously excluding both crawling and flying predators resulted in a c. 23-fold increase in survival. These results suggest that larval predation could be limiting the populations of both broom leaf beetle and Honshu white admiral. Future biocontrol programmes could prioritise candidate agents accordingly.
\end{abstract}

Keywords Biotic interference, Gonioctena olivacea, Limenitis glorifica, food web

\section{INTRODUCTION}

A number of biocontrol agents have been introduced into New Zealand with the intention of reducing populations of invasive weeds. Introducing a new biocontrol agent is costly and time-consuming yet most weed biocontrol agents fail to control the target weed (McFadyen 1998). Possible reasons for failure include: climatic mismatches; population-level compensation of the plant; top-down forces such as predation; or bottom-up forces, like plant quality (Tipping et al. 2013). Two relatively unsuccessful introductions of biocontrol agents into New Zealand have been those of the broom leaf beetle, Gonioctena olivacea L. (Coleoptera: Chrysomelidae) and the Honshu white admiral butterfly, Limenitis glorifica Fruhstorfer (Lepidoptera: Nymphalidae).

The broom leaf beetle is native to Europe and has externally-feeding larvae that defoliate the plant during the summer. It was introduced as a biocontrol agent for Scotch broom Cytisus scoparius (L.) Link (Fabaceae) in 2006. However, this beetle has remained generally rare, and has not had any discernible impact on its host plant since its release (Table S1 in Paynter et al. 2018).

The Honshu white admiral butterfly is endemic to the island of Honshu, in Japan, where it occurs along hedgerows in suburban and rural areas, as well as in forest clearings and field margins in open habitats. Its larvae feed 
externally on the leaves of Japanese honeysuckle (Lonicera japonica Thunb.), a plant that is now a widespread weed in both the North and South Islands of New Zealand. Biological control was considered the only reasonable option left to reduce the prevalence of this vigorous vine and the Honshu white admiral butterfly was first released in New Zealand as a biocontrol agent for Japanese honeysuckle in 2014 (Paynter et al. 2017). The Honshu white admiral established in the Waikato region (Karangahake Gorge; $37^{\circ} 25^{\prime} \mathrm{S}$ $175^{\circ} 43^{\prime} \mathrm{E}$ ) (Paynter et al. 2017), but has apparently failed to establish at several other release sites, including Glen Innes, Auckland (3652'S $\left.174^{\circ} 51^{\prime} \mathrm{E}\right)$ (Landcare Research, unpublished survey data). Moreover, although adult butterflies are conspicuous at Karangahake Gorge, the population density of larvae has to date been insufficient to cause significant defoliation of the target weed (Landcare Research, unpublished survey data).

Paynter et al. (2018) reported that at least nine out of 39 arthropod weed biocontrol agent species, established in New Zealand by 2014, are attacked by parasitoids and/or predators to an extent that is likely to diminish their impacts on their target weeds. They noted that this may be an underestimate because the impact of predation on several agents was unknown so the aim of this study was to investigate the impact of natural enemies on the broom leaf beetle and the Honshu white admiral butterfly as these have not previously been studied in New Zealand.

\section{MATERIALS AND METHODS}

\section{Predation of Gonioctena olivacea larvae}

The experiment was established over 24-28 November 2018 at a site near Palmerston North in the North Island of New Zealand $\left(40^{\circ} 21^{\prime} \mathrm{S}\right.$ $\left.175^{\circ} 35^{\prime} \mathrm{E}\right)$. Newly emerged first-instar G. olivacea larvae bred from beetles collected from a release site at Waiouru $\left(39^{\circ} 27^{\prime} \mathrm{S} 175^{\circ} 40^{\prime} \mathrm{E}\right)$ were placed on c. $40 \mathrm{~cm}$ tall potted Scotch broom seedlings, grown from seed collected at Palmerston North (5 larvae per seedling) randomly allocated to one of the following five treatments: Control (uncaged); 'Tanglefoot' (Contech Enterprises
Inc., Victoria, Canada) applied to create a sticky barrier at the plant base to prevent crawling predators such as ants from accessing the plants; 'Wire cage' using chicken wire mesh (c. 20-mm diameter mesh) sleeves to enclose the seedlings and exclude larger predators, such as birds; 'Fine mesh' (c. 2-mm diameter mesh) to exclude smaller flying predators; and 'Tanglefoot and Fine mesh' to exclude most potential predators. There were twenty replicates of each treatment. During 19-22 December 2018, final instar larvae were counted and the soil in the plant pots was also sieved to check for the presence of prepupae and pupae.

\section{Predation of Limenitis glorifica larvae}

A preliminary experiment was established in November 2017 in the grounds of Landcare Research in Auckland (36 53'S 174 $51^{\circ} \mathrm{E}$ ), to assess predation of the first generation of Limenitis glorifica larvae obtained from a rearing colony established using adults collected from Karangahake Gorge. Using a fine-tipped paint brush, 3-5 newly emerged first-instar larvae were transferred onto potted c. $100-\mathrm{cm}$ tall Lonicera japonica plants, grown specifically for the trial from cuttings collected from plants growing at Birkenhead War Memorial Park, Auckland ( $\left.36^{\circ} 48^{\prime} \mathrm{S} 174^{\circ} 43^{\prime} \mathrm{E}\right)$. Six replicates of two treatments were set up: 'Fine mesh'; and uncaged controls. Plants allocated to the 'Fine mesh' treatment were covered in cylindrical sleeves made from fine-mesh nylon $(30 \mathrm{~cm}$ diameter x $150 \mathrm{~cm}$ height) secured by tying around the base of the stem, which to exclude most potential predators although ants were still capable of accessing the plants via gaps next to the stem. The plants were placed in the grounds of Landcare Research in Auckland (36 $53^{\prime}$ S 174 $\left.51^{\prime} \mathrm{E}\right)$, approximately $1.2 \mathrm{~km}$ from the failed Glen Innes release site, where it was assumed they should be exposed to a similar suite of predators. Plants were spaced sufficiently far apart to ensure they were isolated from each other. Surrounding vegetation was also pruned, if necessary, to prevent larvae and/ or predators gaining access to the plants. Every 2-3 days, treatments were checked to ensure 
the Tanglefoot barriers remained effective and numbers of surviving larvae were counted and the presence of potential predatory invertebrates on the plants was noted. Counts from the census immediately prior to the discovery of the first prepupa were used to estimate final numbers to prevent potential overestimation of predation in uncaged treatments due to larvae dispersing prior to pupation.

A second experiment was set up at the same site in February 2018. The potential for larval mortality due to handling was eliminated by placing c. $100-\mathrm{cm}$ tall Lonicera japonica plants into a shade house containing female Limenitis glorifica butterflies, so that they could oviposit directly onto foliage, avoiding the need to transfer larvae manually. The number of eggs laid on each plant was counted on 20 February 2018, when the plants were moved outside and a factorial experimental design was set up as follows: 'Control' (eggs and larvae exposed to all potential predators); 'Tanglefoot' applied to create a sticky barrier at the plant base to prevent crawling predators such as ants from accessing the plants; 'Fine mesh' (using identical mesh sleeves to those in the preliminary experiment to exclude flying predators but not crawling predators, such as ants); and 'Tanglefoot and Fine mesh' to eliminate all potential sources of predation. Four replicates of the 'Control' and 'Tanglefoot and Fine mesh' treatments and five replicates of the 'Tanglefoot' and 'Fine mesh' treatments were set up. Plants were monitored as per the preliminary experiment.

\section{Statistical analyses}

Data were analysed using Genstat (VSN International Ltd), selecting Generalised Linear Models (GLM) and binomial errors. The dependant variable was the number of larvae or pupae alive in each replicate during the final count. The binomial totals (n) were set to the initial values in each replicate. For the G. olivacea experiment, treatment was included as a factor with five levels ('Control' (uncaged); Tanglefoot'; 'Wire Cage'; 'Fine mesh'; and 'Tanglefoot and Fine mesh'). For Limenitis glorifica, the preliminary experiment included treatment as a factor with two levels ('Control' (uncaged) and 'Fine mesh') and the second experiment had four treatment levels ('Control', 'Tanglefoot', 'Fine mesh', 'Tanglefoot and Fine mesh') and initial number of eggs present was treated as a covariable.

\section{RESULTS}

\section{Predation of G. olivacea larvae}

Treatment had a significant effect on larval survival $\left(\chi^{2}=14.68\right.$, d.f. $\left.=4, \mathrm{P}<0.001\right)$ with a similar proportion of larvae surviving in the 'Tanglefoot' and 'Wire cage' treatments and the controls. In contrast, survival was significantly (c. $5 \mathrm{X}$ ) higher in the 'fine mesh' and 'fine mesh and Tanglefoot' treatments, indicating that fine mesh significantly reduced predation (Fig. 1).

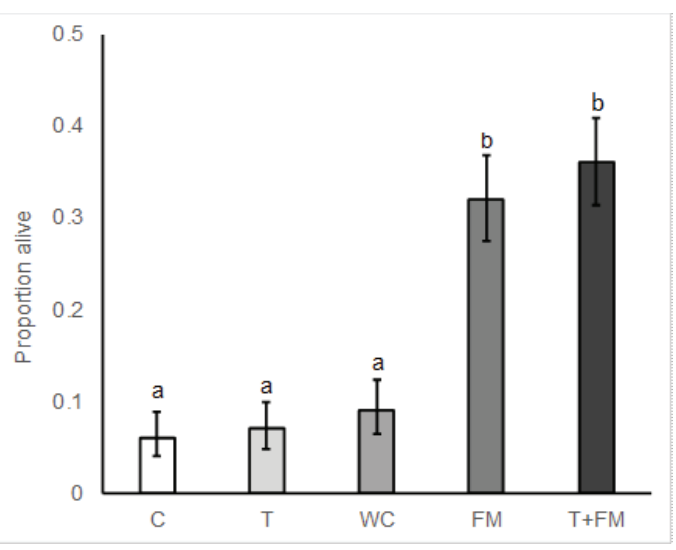

Figure 1 Proportion of $G$. olivacea larvae surviving $+\mathrm{SEM}$ in relation to predator exclusion treatments: $\mathrm{C}=$ Control; $\mathrm{T}=$ Tanglefoot; $\mathrm{WC}=$ Wire cage; $\mathrm{FM}=$ Fine mesh; $\mathrm{T}+\mathrm{FM}=$ Tanglefoot and Fine mesh. Columns with the same letter above them are not significantly different (Fisher's Least Significant Difference).

Presence of predators on the plants was not recorded systematically during the study, although it was noted that spiders (Salticidae, Thomisidae), earwigs (Dermaptera) and ants were commonly present of the Scotch broom foliage and wasps were also seen near the plants but not observed on the foliage. 


\section{Predation of Limenitis glorifica larvae}

In the preliminary experiment, a higher proportion of larvae (c. 35\%) survived in the 'Fine mesh' treatment, compared with the control (c. $7 \%)(\chi 2=6.02$, d.f. $=1, \mathrm{P}<0.05)$.

Treatment also had a significant effect on survival in the second experiment $(\chi 2=18.12$, d.f. 3; $\mathrm{P}<0.001)$ : Survival was very low $(2 \%)$ in the control treatment. Excluding crawling predators with Tanglefoot or sleeving the plants in fine mesh to exclude flying predators, resulted in c. $20 \%$ survival, and excluding both crawling and flying predators in the 'Tanglefoot and Fine mesh' treatment resulted in c. $40 \%$ survival (Fig. 2a). The number of eggs laid on Lonicera japonica plants ranged from 5 to 58 (average c. 20), and the initial number of eggs present $\left(\chi^{2}=24.65\right.$, d.f. $1 ; \mathrm{P}<0.001)$ and the interaction between initial number of eggs present and treatment $(\chi 2=7.10$, d.f. 3; $\mathrm{P}<0.001)$ significantly affected survival. Survival was very low in the uncaged controls, regardless of the initial number of eggs present; survival was low in the Tanglefoot treatment and there was only a weak negative relationship between survival and initial egg number. For both the 'Fine mesh' and 'Tanglefoot and Fine mesh' treatments, survival was high, but there was a strong negative correlation between survival and the initial number of eggs (Fig. 2b).

Predatory invertebrates that were observed on Lonicera japonica foliage comprised praying mantids Miomantis caffra Saussure; coccinelids Harmonia axyridis (Pallas); wasps (Vespula and Polistes spp.); ants Ochetellus glaber (Mayr), Nylanderia sp., spiders Trite parvula (Bryant), and earwigs Forficula auricularia.

\section{DISCUSSION}

It was anticipated that both G. olivacea and Limenitis glorifica should encounter enemy-free space in New Zealand as they both lack similar native 'ecological analogues' (i.e. native species in the region of introduction that are related to the introduced species and share a similar niche, sensu Paynter et al. 2010; Paynter et al. 2018) that could be a source of specialist predators and parasitoids capable of attacking them.

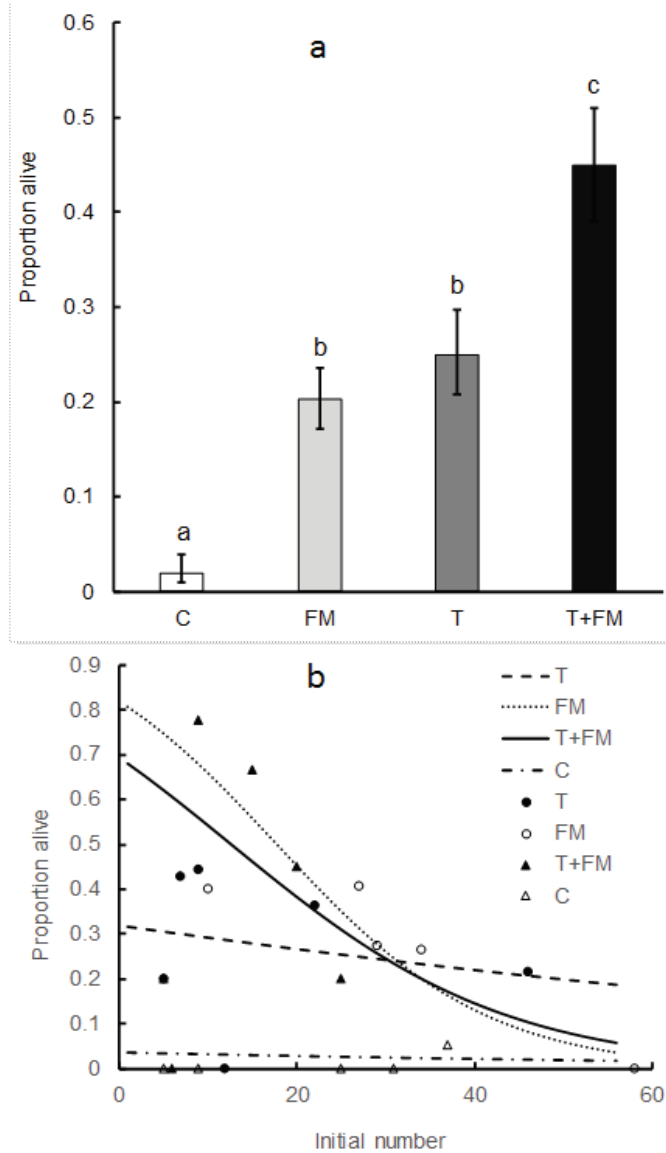

Figure 2 a) Proportion of Limenitis glorifica larvae alive + SEM for the uncaged control and three predator exclusion treatments: $\mathrm{C}=$ Control; $\mathrm{T}=$ Tanglefoot; FM = Fine mesh; T+FM $=$ Tanglefoot and Fine mesh. Columns with the same letter above them are not significantly different (Fisher's Least Significant Difference); b) Proportion of L. glorifica alive for the uncaged control and three predator exclusion treatments in relation to the initial number present. Circles and triangles denote individual data points and the lines indicate the relationship between proportion alive at the end of the experiment and the initial number of eggs per plant.

Nevertheless, predation of both species is clearly very high and potentially explains why G. olivacea is rare in New Zealand and indicates that the 
prospects of Limenitis glorifica being an effective agent may be poor. Indeed, the differences in survival between treatments may have been underestimated in the second experiment with Limenitis glorifica due to density dependent mortality in the 'Fine mesh' and 'Tanglefoot and Fine mesh' treatments indicating that the initial numbers in some replicates may have been too high for the plants to support the development of all larvae.

A range of potential predators were observed on the plants and further work is required to identify the key predators that were excluded by the various treatments. Paynter et al. (2018) reported that biocontrol agents with externally feeding larvae may be especially prone to predation although some agents with externally feeding larvae (e.g. heather beetle Lochmaea suturalis (Thomson) and the alligator weed beetle Agasicles hygrophila Selman and Vogt) reach outbreak densities despite predation. This study provides further evidence that improved prediction of the impact of predation on proposed weed biocontrol agents could greatly assist the selection of effective agents.

\section{ACKNOWLEDGEMENTS}

This work was supported by Strategic Science Investment Funding to Landcare Research from the Ministry of Business, Innovation and Employment.

\section{REFERENCES}

McFadyen REC 1998. Biological control of weeds. Annual Review of Entomology 43: 369-393.

Paynter Q, Fowler SV, Gourlay AH, Groenteman R, Peterson P, Smith L, Winks CJ 2010. Predicting parasitoid accumulation on biological control agents of weeds. Journal of Applied Ecology 47: 575-582.

Paynter Q, Konuma A, Dodd SL, Hill RL, Field L, Gourlay AH, Winks CJ 2017. Prospects for biological control of Lonicera japonica (Caprifoliaceae) in New Zealand. Biological Control 105: 56-65.

Paynter Q, Fowler SV, Groenteman R 2018.

Making weed biological control predictable, safer and more effective: perspectives from New Zealand. BioControl 63: 427-436.

Tipping PW, Martin MR, Pratt PD, Rayamajhi MB, Center TD 2013. An abundant biological control agent does not provide a significant predator subsidy. Biological Control 67: 212219. 